\title{
Gobernar a las mujeres: la proposición XI, 4 del Tratado Político, de Spinoza, o los problemas de la relación naturaleza e historia
}

Govern the Women: The Proposition XI, 4 of the Political Treatise, by Spinoza, or the Problems of the Relationship

between Nature and History

CECILIA ABdo Ferez (iD) a

\section{Resumen}

El texto ${ }^{1}$ interpreta, desde distintas perspectivas posibles, la polémica proposición XI, 4 del último capítulo del Tratado Político de Baruj de Spinoza, donde se sostiene, en el marco de la explicación de distintas formas de democracia, por qué las mujeres estarían excluidas de la participación política. Se remite esta exclusión a la noción de naturaleza en la obra y a su justificación por la historia acaecida, que resultan insatisfactorias, y se propone una conjunción y una superación de ambas interpretaciones, en pos de una lectura posible derivada: la de la producción de la división sexual como régimen político/discursivo; una producción entre develada y consentida por el filósofo.

Palabras clave: Mujeres. Gobierno. Naturalización. Historia. Monismo.

\section{Abstract}

The text interprets, from different perspectives, the controversial proposition XI, 4 of the last chapter of the Political Treaty of Baruch de Spinoza, where it is argued, in the

\footnotetext{
${ }^{1}$ Este texto se presentó con modificaciones en el XIII Coloquio Internacional "Spinoza Maledictus", de Vaquerías, Córdoba, Argentina, en diciembre de 2016, en una mesa dedicada a la proposición aquí en debate.

a Universidad de Buenos Aires-CONICET, Buenos Aires, Argentina/ Universidad Nacional de las Artes, Buenos Aires, Argentina. Doctora en Teoría Política, e-mail: ceciliaabdo@conicet.gov.ar 
context of explaining different forms of democracy, why women would be excluded from political participation. This exclusion is unsatisfactory referred to the notion of nature in the work and its justification by the history. The text proposes a conjunction and an overcoming of both interpretations, in pursuit of a possible reading derived from them: that of the production of the sexual division as a political / discursive regime -a production simultaneously unveiled and consented by the philosopher.

Keywords: Women. Government. Naturalisation. History. Monism.

Dos tentaciones surgen, para el lector habitual de Baruj de Spinoza, frente una mirada rápida de la proposición XI, 4 del Tratado Político (TP): la primera sería explicar la alusión a la "naturaleza de las mujeres", que allí aparece, remitiéndola a la concepción de naturaleza del mismo filósofo, para demostrar que hablar de naturaleza de las mujeres sería autocontradictorio con sus afirmaciones habituales y, por lo tanto, refutable en sus mismos términos ${ }^{2}$. La segunda tentación sería explicar a Spinoza por el contexto: al fin y al cabo, él no sería ni más ni menos hijo de su tiempo que cualquier otro pensador y el límite al progresismo de sus ideas se manifestaría en una opinión tan aparentemente retrógrada como la que él sostiene, en esa proposición, acerca de la posición subordinada, "por necesidad", de las mujeres frente de los hombres ${ }^{3}$. Ambas tentaciones -la primera, la remisión a la coherencia sistemática de su obra y de su término principal, "naturaleza"; la segunda, la justificación historicista de lo dicho-, conducirían a un mismo resultado: salvar a Spinoza, humanizarlo, desacralizarlo y, al menos en este punto del texto,

\footnotetext{
${ }^{2}$ La filosofía de Spinoza, contra el aristotelismo, se afirma contra la definición por género y diferencia específica, en Ética II, XL. Allí se sostiene que todo universal, que todo término genérico, es signo de una imaginación desbordada, que ya no puede distinguir los singulares y agrupa según criterios propios. En esta situación estaría el término universal "mujer", tanto como "hombre". Lo que existen son singulares, modos de la sustancia. Es notable también que, para que haya filosofía práctica, debe haber individualizaciones, en algún sentido, imaginarias, colectivas y relacionales. Esto coloca a la imaginación en el centro del campo de acción -y también del padecimiento-.

${ }^{3}$ La proposición aquí tratada fue objeto de múltiples discusiones desde el feminismo afín a Spinoza, desde definirla como una "cicatriz" en un pensamiento democrático, en el libro de Moira Gatens (1996, p. 134) hasta un "error", explicable por la influencia epocal, en el texto de Beth Lord (2011, p. 1087). En general, sin embargo, se toma como una proposición menor, un ruido molesto, sólo analizada si hay que hacerlo. Para una visión general, ver el texto de Isabel Balza (2014).
} 
dejarlo atrás en el tiempo. Spinoza sería contradictorio, como podemos serlo todos; o efecto de su época, prejuicioso, sexista y ya superado.

Dejarse seducir por cualquiera de esas dos tentaciones (o por ambas), creo, llevaría a no entender lo que dice allí. Sería -sospecho- caer en las trampas que el mismo Spinoza parece haber dejado en el texto; un texto poblado de marcas, de huellas de poder estar argumentando otra cosa, en su literalidad. Sería tomar los atajos que el mismo Spinoza dejó a la vista, para perder definitivamente al lector y, mucho más, a las lectoras posteriores. Sería, en fin, obstaculizar el sentido de una proposición con muchas aristas posibles, algunas de ellas, trabajadas siglos después por el campo teórico feminista. Todo esto, sin desmerecer la posibilidad cierta de que Spinoza, a pesar de todo esfuerzo, resulte insalvable para el feminismo.

En lo que sigue, tomaré esos atajos para, sobre ellos, proponer otra interpretación de TP XI, 4.

\section{La tentación naturalista}

Spinoza se explaya, en esa proposición, sobre el argumento que está desarrollando, desde el inicio del libro XI, para circunscribir quiénes podrían participar políticamente del imperium democrático -el cual, como dice, podría asumir varios tipos, según aquellos a quienes la ley habilite como ciudadanos-. Las condiciones que enumera para ser ciudadano de un imperium democrático son: estar únicamente sometido a las leyes patrias, ser sui juris (o autónomo) y vivir honradamente. Con esto quedarían explícitamente excluidos de la ciudadanía: los peregrinos o migrantes, que "se supone dependen de otro Estado"; "las mujeres y los siervos" (dicho así, con la conjunción "y", que establece una semejanza entre unas y otros, porque ambos "están bajo la potestad de los varones y los señores”); "los niños y los pupilos" (transitoriamente, mientras estén bajo la potestad de padres y tutores); y los criminales. Se podría pensar, además, que dentro de la categoría pupilos se incluirían varios de aquellos que siempre -y no por un tiempo-, precisarán de tutores, como los dementes, los mudos y los socialmente dependientes, con sus trabajos precarios (como se aclara en TP VI, 11, que podría engarzarse con esta 
proposición). Pero sugerir esto sería, quizá, ir más allá de lo que Spinoza quiere decir, en este caso. Las mujeres, entonces, están, excluidas por siempre; ubicadas en un conglomerado social heterogéneo -que va desde migrantes a precarizados y niños-, y puestas en situación de semejanza con los siervos, por estar bajo potestad de otros, los varones (puestos, a su vez, en relación de equivalencia con los amos).

A seguir, Spinoza -de entre todos estos integrantes del conglomerado al que podríamos llamar "resto" de la institución imperium democrático-, enfoca en las mujeres, para explicar específicamente por qué ellas estarían definitivamente excluidas. Y dice:

\begin{abstract}
Más quizá pregunte alguno si acaso las mujeres están bajo la potestad de los hombres por naturaleza o por ley (instituto). Ya que, si ese hecho sólo se fundara en una ley, ninguna razón nos forzaría a excluirlas del gobierno. Ahora bien, basta consultar a la misma experiencia para comprobar que ello se deriva de su debilidad (imbecilitate). Pues no ha sucedido en parte alguna que reinaran a la vez los hombres y las mujeres, sino que en cualquier punto de la tierra donde se hallan hombres y mujeres, vemos que los hombres gobiernan y las mujeres son gobernadas, y que, de esta forma, ambos sexos viven en concordia. [...] Ahora bien, si las mujeres fueran iguales por naturaleza a los varones y poseyeran igual fortaleza de ánimo e igual ingenium (tal es el mejor índice de la potencia y por tanto, del derecho humano), sin duda que, entre tantas y diversas naciones, se encontrarían algunas en que ambos sexos gobernaran por igual, y otras en que los varones fueran gobernados por las mujeres y fueran educados de forma que su poder intelectual fuera menor. Pero, como esto no sucedió en parte alguna, podemos afirmar rotundamente que las mujeres no tienen, por naturaleza, un derecho igual al de los hombres, sino que, por necesidad, son inferiores a ellos. No puede, por tanto, suceder que ambos sexos gobiernen a la par, y mucho menos, que los varones sean gobernados por mujeres ${ }^{4}$.
\end{abstract}

La argumentación parece construida de este modo: ante la pregunta de por qué las mujeres están bajo potestad de los hombres, se dan dos posibilidades, o bien por naturaleza o bien por institución (o ley). Si fuera por institución (o ley), es decir, por convención, no habría razón para excluirlas ("ninguna razón nos forzaría”, dice Spinoza, incluyéndose entre los que excluyen). Quedaría entonces la explicación por la naturaleza, como la única válida. Pero, en lugar de seguir explícitamente este camino, Spinoza propone consultar a la experiencia histórica, a cómo han sucedido las cosas hasta allí. Propone, es decir, una identificación entre naturaleza e historia acaecida, una identificación que justamente repone la convención, igualada ahora a

\footnotetext{
${ }^{4}$ Mis negritas.
} 
naturaleza, que está igualada a historia transcurrida ${ }^{5}$. Una vez supuesto que la explicación válida para la sujeción de las mujeres es la naturaleza (historizada), afirma que si las mujeres fueran iguales a los hombres, tendrían igual fortaleza de ánimo e igual ingenium que ellos (o igual fuerza de inteligir y actuar), o, lo que es lo mismo, iguales derechos naturales e iguales potencias. $O$ para decirlo historizadamente, si las mujeres hubieran conseguido ser históricamente iguales a los hombres, tendrían igual fortaleza de ánimo e igual fuerza de inteligir y actuar que ellos, y por eso, iguales derechos y potencias que ellos. Y si esto fuera así, si tuviesen igual ánimo e igual fuerza de inteligir y actuar, en alguna nación hubiesen gobernado, aunque más no sea con los hombres. Dado que esto no se comprueba, debe deducirse que las mujeres son, "por necesidad", inferiores. Lo que convierte al argumento en una evidente tautología, en una descripción fáctica o, peor, en una afirmación moral del tipo: "esto no se dio, por algo será". El anti-binarismo de Spinoza, ese que rechaza -entre otras- la distinción naturaleza-cultura, serviría aquí para justificar y reproducir una desigualdad dada.

Algunas marcas del texto, para desglosarlo mejor (o más spinocistamente): las mujeres, puestas en un presente naturalizado, tienen con los hombres una diferencia de ingenium, que deriva en una diferencia en derechos naturales. Dado que la pregunta spinocista no es qué es un cuerpo, sino qué puede, lo que las mujeres pueden o podían entonces, las define como cuerpos menos complejos que los de los hombres, cuerpos que no son suijuris. Es decir, algo de los cuerpos de las mujeres, históricamente devenidos como tales, expresa una potencia tan menor como para no contar igual políticamente; o, en otras palabras, esos cuerpos femeninos se constituyen menos del intercambio con otros cuerpos - desde libros a personas-, se alimentan menos de ellos, son más pobres en virtud de ese menor intercambio de experiencias con ellos; algo de su deseo históricamente constituido ha devenido deseo de servidumbre, deseo de no gobernar, sino de ser gobernadas -excepto en el caso de las amazonas citadas por Spinoza, quienes, para continuar con su gobierno,

\footnotetext{
${ }^{5}$ Si esto fuera así, la afirmación spinocista de la potencia infinita de la naturaleza naturante, o Dios, sería rebajada al transcurrir de la experiencia histórica efectivamente acaecida, a un despliegue de lo sucedido en el pasado, a una totalidad cerrada y pasada. 
mataban a los varones recién nacidos; esto es, se desprendían inmediatamente del Otro amenazante-.

Un argumento como éste de Spinoza, basado en la identificación de naturaleza e historia acaecida, claro que podría invertirse: si la naturaleza es la historia tal como se ha dado, y esto significa que las mujeres son cuerpos menos complejos, más pobres en intercambios que los regeneren, con deseos de servidumbre y menor potencia de intelección y de acción, un cambio histórico en esa naturaleza -un enriquecimiento de sus experiencias con otros cuerpos, por ejemplo- devendría en una nueva correlación de potencias y derechos y esto seguiría llamándose "naturaleza de las mujeres". El argumento, en ese caso, podría tomarse como si fuese una cachetada para las mujeres: mujeres, esto han devenido, no se les reconocerá normativamente nada, ni se las incluirá políticamente por ninguna buena conciencia, porque ésta no es una filosofía normativa; si quieren mudar las condiciones de su exclusión política, modifiquen su naturaleza, complejicen sus cuerpos con otros intercambios, deseen la emancipación, actúen y piensen de acuerdo a una nueva riqueza adquirida. Pero eso sería, justamente, un argumento normativo, y no sólo normativo, sino teleológico: mujeres, quieren gobernar y gobernarse, sean como nosotros, los hombres, el tipo ideal.

Otro desarrollo posible del argumento naturalista, más adecuado para lectores especializados de la obra, sería decir: la naturaleza en Spinoza no es un orden compuesto de géneros, especies, sexos, básicamente porque su estructura es nominalista, porque lo que hay en ella son singularidades y porque los universales como el universal hombre o mujer-, son productos de una imaginación desbordada, que aúna y generaliza, cuando ya no puede concebir lo particular. El problema de las mujeres, entonces, no sería sólo de las mujeres, porque en la obra de Spinoza los cuerpos se distinguen -además de por su potencia-, por sus grados de complejidad y, en términos estrictos, no hay una diferencia específica que determine a partir de cuándo se está hablando de un animal complejo o de un humano. Spinoza renuncia a determinar en base a ciertos atributos ideales (por ejemplo, la racionalidad) cuál sería la diferencia antropológica, cuál sería la esencia humana específica y distintiva de los humanos respecto de los animales más complejos: todos los cuerpos singulares están de algún modo animados y hay hombres tan reducidos en 
sus posibilidades de intercambio con otros hombres y con las cosas, que, en su pobreza, son infantilizados o bestializados -un caso así, justamente, es el que tratamos, de las mujeres-.

¿Qué puede un cuerpo humano, si no hay esencia a priori que lo defina como tal? No qué es, sino ¿qué puede? Ese cuerpo puede desarrollar la aptitud de intercambio, de hacer y padecer de varias maneras al mismo tiempo, de percibir varias cosas al mismo tiempo, correlativa a la aptitud de su alma para conocer distintamente muchas cosas. Que no haya una diferencia antropológica específica, determinada de antemano, entre los cuerpos animales de cierta complejidad y los humanos, abre, como dirá Matheron, a la definición dinámica del semejante, correlativa a una práctica política, económica, ética (1978). Que no haya cuerpo ni alma definidos de antemano como cuerpos y almas sexuados (pero tampoco asumidos como neutros, como en toda la tradición filosófica clásica), repone la pregunta práctica por el desarrollo de las mujeres y los hombres, en condiciones históricamente dadas. No en vano las mujeres están puestas, en la proposición que tratamos, en una intersección de sujetxs-resto, definidos como tales por una estructura histórica que reduce, minimiza sus posibilidades de despliegue del hacer y del inteligir, correlativos a la restricción de sus derechos naturales y sus derechos políticos.

\section{La tentación historicista}

Sin embargo, Spinoza habla de las mujeres y de los hombres, como si lo anterior no hubiese sido escrito por él. Habla, mucho más, de la existencia de sexos, como universales dados en la naturaleza, como diferencia natural. Si los sexos fuesen iguales en potencia, habrían gobernado ambos, dice ${ }^{6} \cdot \sum^{E}$ s posible que, justo en este caso, la filosofía de Spinoza admita la existencia de universales dados? ¿O hay que buscar algo más? Repasemos la parte que nos compete ahora de la proposición:

\footnotetext{
${ }^{6}$ Una pregunta derivada: ¿es ser igual en potencia, necesariamente, asumir el imperativo de gobernar?
} 
Ahora bien, si las mujeres fueran iguales por naturaleza a los varones y poseyeran igual fortaleza de ánimo e igual ingenium (tal es el mejor índice de la potencia y por tanto, del derecho humano), sin duda que, entre tantas y diversas naciones, se encontrarían algunas en que ambos sexos gobernaran por igual, y otras en que los varones fueran gobernados por las mujeres y fueran educados de forma que su poder intelectual fuera menor. Pero, como esto no sucedió en parte alguna, podemos afirmar rotundamente que las mujeres no tienen, por naturaleza, un derecho igual al de los hombres, sino que, por necesidad, son inferiores a ellos.

La clave de la cuestión parecería ser la aparición, por segunda vez (y únicas) en todo el libro, de la palabra "naciones", en el texto: "naciones" se menciona por primera vez en TP IX, 13, para remitir a una comunidad lingüística, y aquí. La presencia de la palabra naciones, que tampoco existe como algo dado en la naturaleza, según el mismo Spinoza, sino como referente geográfico, lingüístico, histórico, construido como singular, da cuenta de que se está aquí, de cara a la división de mujeres y hombres, ante una nominación culturalmente producida. Que se está ante una muestra del poder comunitario del nombrar, jerarquizar y dividir. La alusión a las naciones, como referencia para dilucidar si son o no distintos los hombres y las mujeres, queda asociada no sólo a la producción de la afirmación de la división sexual, sino a la afirmación de la posición subordinada de las mujeres en esa división, como efecto de dispositivos lingüísticos de poder.

Esto permitiría pensar al sexo de tres formas articuladas: primero, sexo es aquel significante construido por las diversas naciones o discursos culturales singulares, para nombrar, para agrupar y otorgar valor a aquel colectivo imaginario subordinado, dadas ciertas propiedades que se adscriben minusválidamente a sus cuerpos. Este colectivo subordinado lo es tanto más, cuantas más características se le atribuye compartir con lo infantil, lo tutelado, lo migrante, lo precarizado, lo débil o imbécil y lo deshonrado; o, en otras palabras, con el resto valorativamente despreciado. Segundo: sexo es aquel significante efecto de una relación de poder, efecto de la división sexual indefinidamente citada y no algo previo a esa división (o, como dirá Monique Wittig, es la opresión sexual la que crea al sexo como significante, como es el racismo el que crea al significante raza, y no viceversa) (WITTIG, 2006, p. 28). Tercero: sexo es aquel significante que precisa de la naturalización, que impone la remisión a una supuesta materialidad distintiva de los cuerpos, a una materia previa y exenta de historia, a una materia puesta en posición 
de base o fundamento explicativo de la desigualdad histórica que vendría después (la sujeción de las mujeres se debe a su "debilidad", dice Spinoza en este caso) (BUTLER, 2002).

Las mujeres, como los hombres, son inteligibles como tales por una comunidad lingüística, o para decirlo en otros términos, son inteligibles desde y por discursos. Mujer u hombre no es una cuestión de ser, sino un resultado de relaciones; en el caso de Spinoza, de relaciones corporales, de prácticas sociales, de individualizaciones en la práctica que tienen por efecto ciertas intelecciones distintivas. Las mujeres, como los hombres, no son ningún grupo natural, en el sentido de reconocible como tal a priori, de creado como tal, sino grupos naturalizados: se produce a las mujeres y a los hombres como grupos naturales, se los construye ideológicamente como tales, se los hace depender de una división sexual que es también una división normativa, indefinidamente reproducida, con su ideal regulatorio de qué se supone que es ser mujer y qué ser hombre -o quiénes se supone que son disidentes de ambos-. Hay producción del sexo mujer, entonces, como categoría lingüístico-política, inmediatamente inserta en relaciones de sujeción de todo tipo, inmediatamente expuesta a violencias de todo tipo, desde económicas y jurídicas hasta educativas y neocoloniales (relaciones de sujeción y de violencia que pueden invertirse sin cambiar el esquema, como en el caso de las Amazonas citado por Spinoza, en el que sólo cambiaría el sujeto opresor). Hay producción del género, como aquello historizado respecto de la materia de los cuerpos, de la materia del sexo, biológicamente connotado y puesto en el origen, un origen que justificaría lo históricamente acaecido (una esencialización del cuerpo material, que puede, sin embargo, ser estratégicamente asumida para las luchas, como se discute actualmente en la Argentina, en el contexto de las luchas por "Ni una menos").

La alusión a las naciones en este texto, aquí retraducidas como discursos y lenguas, pone al sexo en el marco en que debe discutírselo, como efecto lingǘstico, como significante naturalizado de una relación de poder citada indefinidamente, con variaciones, a lo largo de las historias y de cuya norma hegemónica resultan las mujeres y los varones, como diferencia evidente, como si fuese una diferencia natural. 


\section{Otra interpretación posible (y derivada)}

Explicar esta proposición ya sea por su remisión contradictoria al concepto naturaleza, en la obra spinocista, o desde una posición crítica contemporánea, reduciría - a pesar de sus "momentos de verdad" y de la imposibilidad tanto de fusionar como también de distinguir completamente naturaleza e historia, en su monismo- mucho lo que Spinoza está sugiriendo aquí. El texto, como se dijo, está poblado de marcas que exigen leer entrelíneas: la identificación entre naturaleza e historia acaecida, para justificar una posición subordinada; la referencia a las naciones, como dispositivo lingüístico de producción de una división sexual asumida como dada y natural, y la más relevante y en apariencia menos impactante, la alusión a la concordia que acarrearía mantener esa división sexual como organización paralela, como axioma o prolegómeno necesario de una institucionalidad política democrática. Dice Spinoza:

Pues no ha sucedido en parte alguna que reinaran a la vez los hombres y las mujeres, sino que en cualquier punto de la tierra donde se hallan hombres y mujeres, vemos que los hombres gobiernan y las mujeres son gobernadas, y que, de esta forma, ambos sexos viven en concordia.

Y culmina:

Y, si consideramos, además, los afectos humanos, a saber, que los hombres casi siempre aman a las mujeres por el solo afecto sexual y que aprecian su talento y sabiduría en la misma medida en que ellas son hermosas; y que, además, los hombres soportan a duras penas que las mujeres que ellos aman favorezcan de algún modo a otros, y hechos por el estilo, veremos sin mayor dificultad que no puede acontecer, sin gran perjuicio para la paz, que los hombres y las mujeres gobiernen por igual.

¿Qué tienen que ver la paz y la concordia, frente a una diferencia que, si seguimos la literalidad del argumento, sería natural? ¿O acaso se podría decir que sería mejor para la paz y la concordia que el pez grande se coma al chico, como aparece en su ejemplo de un derecho natural no normativo? ¿Desde cuándo el criterio para entender los derechos naturales en Spinoza es si los seres se relacionan entre ellos siguiendo la paz y la concordia? ¿Por qué muestra tanta aversión al conflicto, Spinoza, en este caso?

La alusión a la paz y la concordia desmiente absolutamente el argumento de la naturaleza para fundamentar la división sexual. No hay ninguna naturaleza aquí (en el 
sentido clásico del término, en el sentido anti-spinocista de lo esencial, lo inmutable y lo dado a priori), sino que la división sexual y la sujeción de un sexo/género respecto de otro es sugerido, casi gritado por Spinoza, como lo que es: un régimen político de producción de esa división. Hay, se lee, un régimen político de producción de la división sexual, mucho más, de la heterosexualidad como relación dominante entre los sexos. Pero ese régimen no debe ser expuesto como si fuese un artificio, salvo que se quiera quebrar la concordia, porque funciona como prolegómeno, como organización social paralela, necesaria y absolutamente conviviente con cierto tipo de instituciones democráticas.

Si esto fuera así, si esto estuviera diciendo Spinoza, puede decirse, con el feminismo posterior, que la producción político/discursiva de la división sexual se seguirá viendo como diferencia natural entre los sexos, como diferencia que sólo debe ser asumida como tal, como normalidad y calma, salvo que algún conflicto la muestre, ya no como mera diferencia, sino en tanto oposición, y esto quiebre la concordia del régimen de sujeción. El carácter político de la diferencia sexual sólo se verá si hay luchas porque, antes del conflicto, la relación entre los sexos sólo aparece como diferencia natural, cuya recitación aproblemática trae paz y buena socialización. Para politizar la diferencia, para mostrarla como efecto de un régimen político/discursivo de producción de la sexualidad, hay que asumir también el riesgo de deconstruir los sexos/géneros como tales, es más, como imaginarios-cárceles, sobre todo en el caso de las mujeres: algo que seguramente no traerá concordia ni paz, ni para la estructura social, ni para lxs sujetxs, como singularidades.

Esto parece poder leerse en Spinoza, con su ambigüedad entre el develamiento y la conformidad. Dice, aún más, para reforzarlo: si ambos sexos fueran iguales en ánimo e ingenium, entre tantas naciones, se encontraría alguna nación en donde gobernaran por igual y "otras en que los varones fueran gobernados por las mujeres de forma que su poder intelectual fuera menor". Gobernados de forma que su poder intelectual fuera menor. Es decir, gobernados para seguir siendo gobernados. Más allá de toda confianza desmedida en los poderes de la educación, lo que parece decir Spinoza -y ya no está claro si en entrelíneas-, es que el régimen político/discursivo de producción de la división sexual se sostiene perpetuando que uno de los géneros -el de las mujeres y el todos aquellos inteligibles como emparentados con ellas-, siga teniendo menor educación, menor acceso a los bienes, derechos políticos restringidos, cuerpos menos 
complejos por menor intercambio con otros (y por atadura gozosa al ideal regulativo y asfixiante del cuerpo feminizado), y menor acceso a los placeres. Algo de la paz y la concordia que ha permitido la existencia del espacio público y político modernos se sostiene en que esa división y esa jerarquización de sexos se asuman como ancladas en una naturaleza esencialista, inmóvil y clasificatoria, supuestamente corroborada por la indefinida recitación tautológica de historias de debilidad que mostrarían que, si las mujeres han estado sojuzgadas hasta ahora y no ha sido más que excepcionalmente de otro modo, por algo será, y que, si ellas quieren otra cosa, habrá desorden, conflicto, violencia, irreverencia ante lo que siempre ha sido normalizado y que eso no quedará impune. Esto es, pareciera leerse desde esta proposición de Spinoza, que hay ciertas asunciones de identidades colectivas que no suman concordia a la vida de la comunidad, porque socavan el suelo de dominación que sostiene esa concordia.

En eso estamos.

\section{Bibliografía}

BALZA, I. Los feminismos de Spinoza: corporalidad y renaturalización. Revista Daimon. Revista Internacional de Filosofía, n. 63, p. 13-26, 2014.

BUTLER, J. Cuerpos que importan. Sobre los limites materiales y discursivos del «sexo». Buenos Aires: Paidós, 2002.

GATENS, M. Imaginary Bodies. Ethics, Power and Corporeality. Londres y Nueva York: Routledge, 1996.

LORD, B. 'Disempowered by Nature': Spinoza on The Political Capabilities of Women. British Journal for the History of Philosophy, v. 19, n. 6, p. 1085-1106, 2011.

MATHERON, A. L'anthropologie spinoziste? Revue de Synthèse, Centre International de Synthèse, París, tomo 99, p. 174-185, 1978.

SPINOZA, B. Tratado político. Madrid: Alianza Editorial, 1986.

WITTIG, M. El pensamiento heterosexualy otros ensayos. Madrid: Egales, 2006.

RECIBIDO: $17 / 11 / 2019$

APROBADO: 02/06/2020

RECEIVED: $11 / 17 / 2019$

APPROVED: 06/02/2020 